\title{
Compressibilidade de um Argissolo Vermelho-Amarelo trafegado e escarificado
}

\author{
Compressibility of a trafficked and chiseled Alfisol
}

\author{
Eduardo Saldanha Vogelmann ${ }^{{ }^{*}}$ Marcelo Ivan Mentges ${ }^{\mathrm{I}}$ José Miguel Reichert $^{\mathrm{II}}$ \\ David Peres da Rosa ${ }^{\mathrm{III}}$ Cláudia Alessandra Peixoto de Barros ${ }^{\mathrm{I}}$ Dalvan José Reinert ${ }^{\mathrm{II}}$
}

RESUMO

O tráfego de máquinas agrícolas é considerado uma das principais fontes da compactação do solo. Uma prática utilizada para minimizar os efeitos da compactação é a escarificação, porém a haste escarificadora pode causar compactação subsuperficial. O objetivo deste trabalho foi avaliar a influência do tráfego de máquinas na compressibilidade de um Argissolo Vermelho-Amarelo distrófico arênico, de textura franco arenosa e avaliar o comportamento mecânico desse solo abaixo da linha de atuação da haste escarificadora. Os tratamentos investigados foram: semeadura direta há 13 anos, semeadura direta há 13 anos com tráfego adicional (intensidade de tráfego de $24,67 \mathrm{Mg} \mathrm{km} \mathrm{ha}^{-1}$ ), cultivo mínimo recém implantado e cultivo mínimo recém implantado com tráfego adicional. Para a determinação da densidade do solo, de índice de vazios, da pressão de preconsolidação e do coeficiente de compressão, foram coletadas amostras nas camadas de 0,0-0,10m, 0,10-0,20m, 0,20-0,30m e 0,30-0,40m. O tratamento semeadura direta há 13 anos apresentou a menor capacidade de suporte e maior suscetibilidade à compactação.

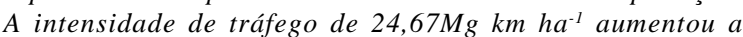
densidade do solo e reduziu o índice de vazios até 0,20m. A escarificação não afetou a pressão de preconsolidação e o coeficiente de compressão do solo na camada abaixo da linha de atuação da ponteira do escarificador.

Palavras-chave: compactação do solo, pressão de preconsolidação, coeficiente de compressão, cultivo mínimo.

\section{ABSTRACT}

Farm machinery wheeling is considered a major source of soil compaction. The use of chisel plow can minimize such effects, but the chisel can cause subsurface compaction. The aim of this study was to evaluate the effect of traffic and is present below the compaction layer thought compressive parameters of soil. The treatments investigated were: no-tillage, no-tillage with additional traffic (traffic intensity of $24.67 \mathrm{Mg}$

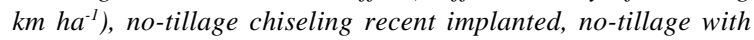
additional traffic and chiseling recent implanted. For the density, void ratio, preconsolidation pressure and coefficient of compressibility determination in the layers $0.0-0.10 \mathrm{~m}, 0.10$ $0.20 \mathrm{~m}, 0.20-0.30 \mathrm{~m}$ and 0.30 to $0.40 \mathrm{~m}$ samples were collected. The treatment no-tillage showed the lowest load support capacity and greater susceptibility to compaction. The

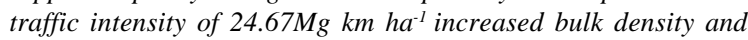
decreased void ratio until $0.30 \mathrm{~m}$ depth. The chisel plow did not affect the preconsolidation pressure and coefficient of compressibility of soil layer below the line of action of the chisel tip.

Key words: soil compaction, preconsolidation pressure, coefficient of compressibility, chiseling.

\section{INTRODUÇÃO}

Desde o início da mecanização agrícola brasileira, tem-se reservado atenção ao tráfego de máquinas agrícolas, considerado como a principal fonte de compactação do solo (HORN \& FLEIGE, 2003). Esse, juntamente com o aumento da massa das máquinas e equipamentos agrícolas e a errônea pressão de insuflação dos pneus são fontes potencializadoras do processo de compressão do solo quando na realização

IPrograma de Pós-graduação em Ciência do Solo, Universidade Federal de Santa Maria (UFSM), 97105-900, Santa Maria, RS, Brasil. E-mail: eduardovogelmann@hotmail.com. *Autor para correspondência.

IDepartamento de Solos, UFSM, Santa Maria, RS, Brasil.

IIIInstituto Federal do Rio Grande do Sul, Campus Sertão, Sertão, RS, Brasil. 
das práticas de manejo, principalmente quando o solo está acima do ponto de friabilidade e próximo ao limite plástico (HÅKANSSON, 2005). O risco de compactação é elevado quando as pressões aplicadas ao solo são maiores do que a capacidade de suporte de carga, sendo a umidade uma das responsáveis pela redução da capacidade de suporte (ALAKUKU et al., 2003).

As principais modificações causadas pelo processo de compactação podem ser visualizadas nas propriedades físicas do solo, pronunciadas pelo aumento na densidade, com consequente aumento da resistência mecânica do solo e redução da macroporosidade (REICHERT et al., 2007). Quando em demasia, a compactação pode reduzir a infiltração e a distribuição de água, além de dificultar a penetração das raízes no perfil do solo, o que pode limitar a absorção de nutrientes pelas plantas. Tudo isso poderá originar queda na produção das culturas (SUZUKI et al., 2008), bem como favorecer a ocorrência de processos erosivos (REICHERT et al., 2007).

A escarificação é uma das alternativas recomendadas para reduzir a compactação dos solos (CAMARA \& KLEIN, 2005). Esta prática aumenta a porosidade e reduz a densidade (REICHERT et al., 2009a), sendo que ao mesmo tempo rompe as camadas compactadas. Em função disso, a escarificação eleva a taxa de infiltração e a capacidade de armazenamento de água (CAMARA \& KLEIN, 2005) e reduz a resistência mecânica do solo à penetração das raízes, favorecendo o seu desenvolvimento (REICHERT et al., 2009a). Contudo, o uso contínuo de ferramentas estreitas no solo, como hastes escarificadoras, pode proporcionar compactação em camadas abaixo da linha escarificada (COHRON, 1971). Essa compactação subsuperficial pode impedir o aprofundamento do sistema radicular e também diminuir a infiltração de água no solo (CAMARA \& KLEIN, 2005). Assim, especula-se sobre a formação de um "pé-de-escarificador", a exemplo do "pé-de-grade", observado por STONE \& SILVEIRA (1999) em um Latossolo.

Algumas investigações sobre a ocorrência de camadas compactadas em solos sob semeadura direta e escarificados foram realizadas (MENTGES, et al., 2010). Nessas, foram avaliadas apenas propriedades físico-hídricas. Entretanto, estudos sobre propriedades mecânicas são limitados, porém importantes para a validação dessa técnica de manejo e conservação de solos cultivados sob semeadura direta e que apresentam elevado grau de compactação. Dessa forma, o objetivo deste trabalho foi avaliar a influência do tráfego de máquinas na compressibilidade de um Argissolo Vermelho-Amarelo e avaliar o comportamento mecânico desse solo abaixo da linha de atuação da haste escarificadora.

\section{MATERIAL E MÉTODOS}

O estudo foi realizado no ano de $2007 \mathrm{em}$ um Argissolo Vermelho-Amarelo distrófico arênico (EMBRAPA, 2006), de textura franco arenosa, com aproximadamente $600 \mathrm{~g} \mathrm{~kg}^{-1}$ de areia, $200 \mathrm{~g} \mathrm{~kg}^{-1}$ de silte e $200 \mathrm{~g} \mathrm{~kg}^{-1}$ de argila. Maiores detalhes da granulometria e da densidade de partículas estão em MENTGES et al. (2010). O solo está localizado na área experimental do Departamento de Solos da Universidade Federal de Santa Maria, no município de Santa Maria, Rio Grande do Sul. A área está situada a 100m de altitude e o clima da região é enquadrado segundo classificação de Köppen na zona Cfa (NIMER, 1989).

Os tratamentos foram distribuídos no campo em blocos ao acaso, em parcelas subdivididas, com três repetições para cada tratamento. Nas parcelas principais, foram casualizados os tratamentos semeadura direta há 13 anos (SD) e semeadura direta há 13 anos com tráfego adicional (TA). Nas subparcelas, foram casualizados os níveis do segundo fator de variação (com escarificação e sem escarificação), constituindo assim mais dois tratamentos: cultivo mínimo (SDesc) e cultivo mínimo com tráfego adicional (TAesc), ambos recém implantados.

O tráfego adicional foi executado com uma pá carregadora, marca Case, modelo W18, com massa total de $8,531 \mathrm{Mg}$. A concha foi preenchida de solo para aumentar a massa no eixo frontal do equipamento, o que garantiu uma distribuição uniforme de $10 \mathrm{Mg}$. Os pneus eram Firestone 14-24, sendo que as garradeiras se encontravam desgastadas pelo uso, evitando assim o cisalhamento superficial. A pressão de inflação dos pneus foi de $276 \mathrm{kPa}$, gerando uma pressão de contato pneu/solo de $260,7 \mathrm{kPa}$. A pressão de contato pneu/ solo foi calculada dividindo a massa total do trator por roda pela área de contato, tomando por base uma distribuição de $35 \%$ da massa para eixo traseiro e $65 \%$ para o eixo dianteiro, adicionando a massa da concha repleta de solo no eixo dianteiro. A área de contato foi mesurada com a delimitação da área de contato pneusolo no campo com farinha, momento em que uma foto digital foi tirada e após efetuou-se a medição da área com uso de software CAD.

Foram executadas duas passadas com a pá carregadora na velocidade de $1 \mathrm{~km} \mathrm{~h}^{-1}$, o que resultou em uma intensidade de tráfego de $24,67 \mathrm{Mg} \mathrm{km} \mathrm{ha}^{-1}$, estimada pela equação proposta por HÅKANSSON, (2005). A compactação foi realizada de modo que os pneus comprimissem áreas paralelas entre si, executando passadas sobrepostas às anteriores, para que toda a área fosse igualmente trafegada. No momento da compactação, a área encontrava-se coberta com azevém (Lolium multiflorum Lam.), com massa 
de matéria seca de $1,43 \mathrm{Mg} \mathrm{ha}^{-1}$. O teor médio de água no solo no momento da compactação era de $0,15 \mathrm{~kg} \mathrm{~kg}^{-1}$. Maiores detalhes do teor de água no solo, além dos limites de liquidez e plasticidade e o índice de plasticidade do solo em estudo estão dispostos em MENTGES et al. (2010). A escarificação foi realizada na profundidade teórica de trabalho de $0,2 \mathrm{~m}$ de profundidade, com um escarificador de três hastes, espaçadas em $0,4 \mathrm{~m}$. No momento da operação, o solo encontrava-se com um teor de água de $0,155 \mathrm{~kg} \mathrm{~kg}^{-1}$.

As amostragens foram realizadas aproximadamente um mês após a compactação. Para avaliar o efeito do tráfego, amostras de solo foram coletadas na camada de $0,0-0,1 \mathrm{~m}$ e $0,1-0,2 \mathrm{~m}$. O efeito da haste escarificadora abaixo da sua linha de atuação foi avaliado em amostras coletadas nas camadas de 0,2$0,3 \mathrm{me} 0,3-0,4 \mathrm{~m}$

Amostras de solo com estrutura preservada, coletadas em cilindros metálicos de $0,061 \mathrm{~m}$ de diâmetro de $0,03 \mathrm{~m}$ de altura, foram homogeneizadas quanto ao potencial matricial em câmara de pressão de Richards, a um potencial matricial de $-33 \mathrm{kPa}$. Após, as amostras foram submetidas ao ensaio de compressão uniaxial, seguindo a NBR-12007/90 (ABNT, 1990), com alteração no tempo de aplicação das cargas. Cargas estáticas de 12,$5 ; 25 ; 50 ; 100 ; 200 ; 400 ; 800$ e 1600kPa foram aplicadas durante um período de cinco minutos, período suficiente para atingir $99 \%$ da deformação máxima (SILVA et al., 2000).

Após esse ensaio, as amostras foram secas em estufa a $105^{\circ} \mathrm{C}$, durante 24 horas e, a partir da massa seca e do volume do solo, foi determinada a densidade do solo (Ds) (BLAKE \& HARTGE, 1986). Para a determinação da pressão de preconsolidação (sp), coeficiente de compressão (Cc), densidade do solo e índice de vazios (e), foi utilizado o software Compress (REINERT et. al., 2003), optando-se pelo método de Casagrande (HOLTZ \& KOVACS, 1981), com ajuste semi-manual (método 2). As curvas de compressão foram normalizadas, ou seja, dividiu-se o coeficiente de compressão e a densidade após cada pressão aplicada pelo índice de vazios e densidade inicial de cada amostra.

A análise estatística constou de análise da variância e comparação de médias pelo teste de Tukey a 5\% de significância.

\section{RESULTADOS E DISCUSSÃO}

O índice de vazios (e), a densidade do solo (Ds), a pressão de preconsolidação (sp) e o coeficiente de compressão (Cc) do Argissolo sob sistema de semeadura direta e com tráfego adicional encontramse na tabela 1. Não houve diferença estatística

Tabela 1 - Densidade do solo (Ds), índice de vazios (e), tensão de pré-consolidação $\left(\sigma_{\mathrm{p}}\right)$ e coeficiente de compressão do Argissolo VermelhoAmarelo.

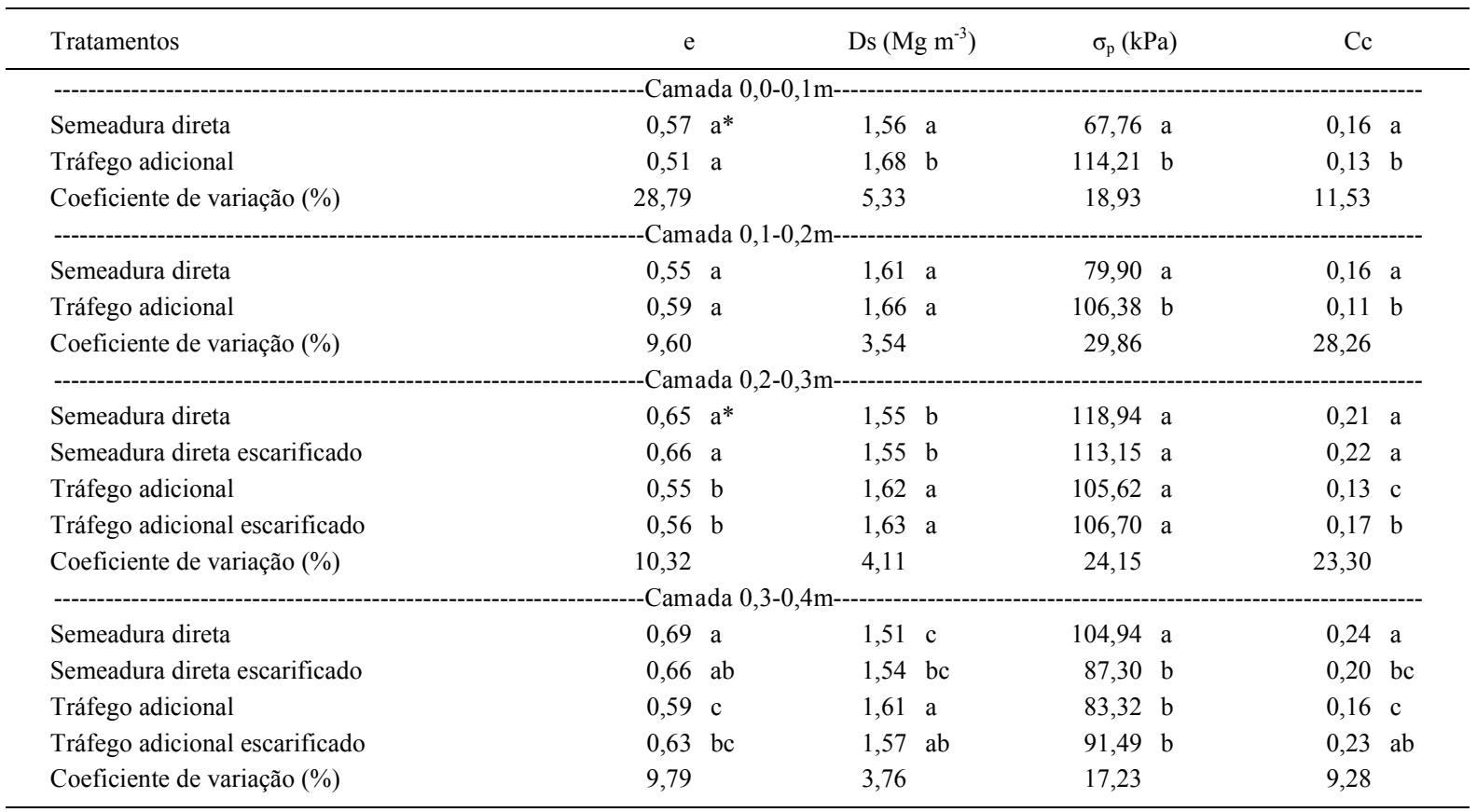

*Médias seguidas da mesma letra não diferiram estatisticamente pelo teste de Tukey a 5\% de probabilidade. 
significativa para o índice de vazios nas camadas avaliadas. Porém, o tráfego adicional (TA) elevou a densidade do solo em relação ao sistema de semeadura direta (SD) na primeira camada (respectivamente, 1,68 e $1,56 \mathrm{Mg} \mathrm{m}^{-3}$ ). No entanto, os valores de densidade permaneceram abaixo de $1,74 \mathrm{Mg} \mathrm{m}^{-3}$, valor crítico ao crescimento de plantas para solos com teor de argila de aproximadamente $20 \%$ (REICHERT et al., 2009b).

O tráfego da pá carregadora afetou a compressibilidade do solo nas camadas de $0-0,10 \mathrm{~m}$ e 0,10-0,20m, pois elevou os valores de pressão de preconsolidação e reduziu o coeficiente de compressão em ambas as camadas (Tabela 1), quando comparado ao tratamento $\mathrm{SD}$. Tal comportamento deve-se à maior densidade observada no tratamento TA, a qual, por mais que diferenças significativas não tenham sido observadas na segunda camada, foi maior em ambas as camadas. Em um Argissolo Amarelo, o maior estado de compactação e a agregação mais compacta das partículas do solo, avaliados por SILVA \& CABEDA (2006), tornam-no menos suscetível à compressão.

As curvas de compressão normalizadas são apresentadas na figura 1 . Na camada de $0-0,1 \mathrm{~m}$, o tratamento SD apresentou maior redução no índice de vazios (Figura 1A) e aumento na densidade do solo (Figura 1B), sendo que as diferenças em relação ao tratamento TA foram mais evidentes quando cargas a partir de $100 \mathrm{kPa}$ foram aplicadas ao solo. Na camada de 0,10-0,20-m (Figura 2), um comportamento semelhante foi observado, porém as diferenças na redução do índice de vazios e aumento da densidade foram observadas, respectivamente, nas cargas de $400 \mathrm{kPa}$ e

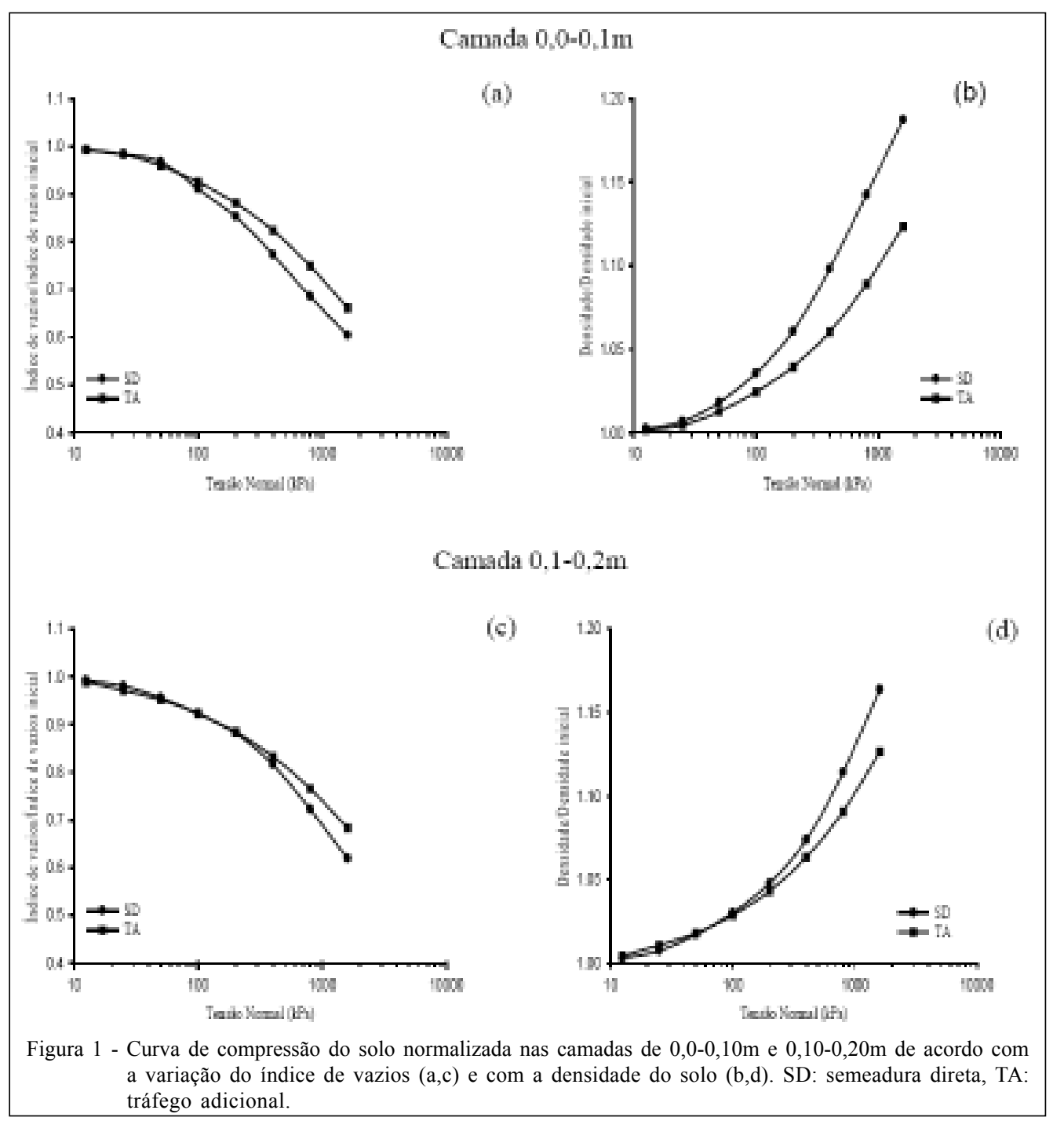

Ciência Rural, v.42, n.2, fev, 2012. 

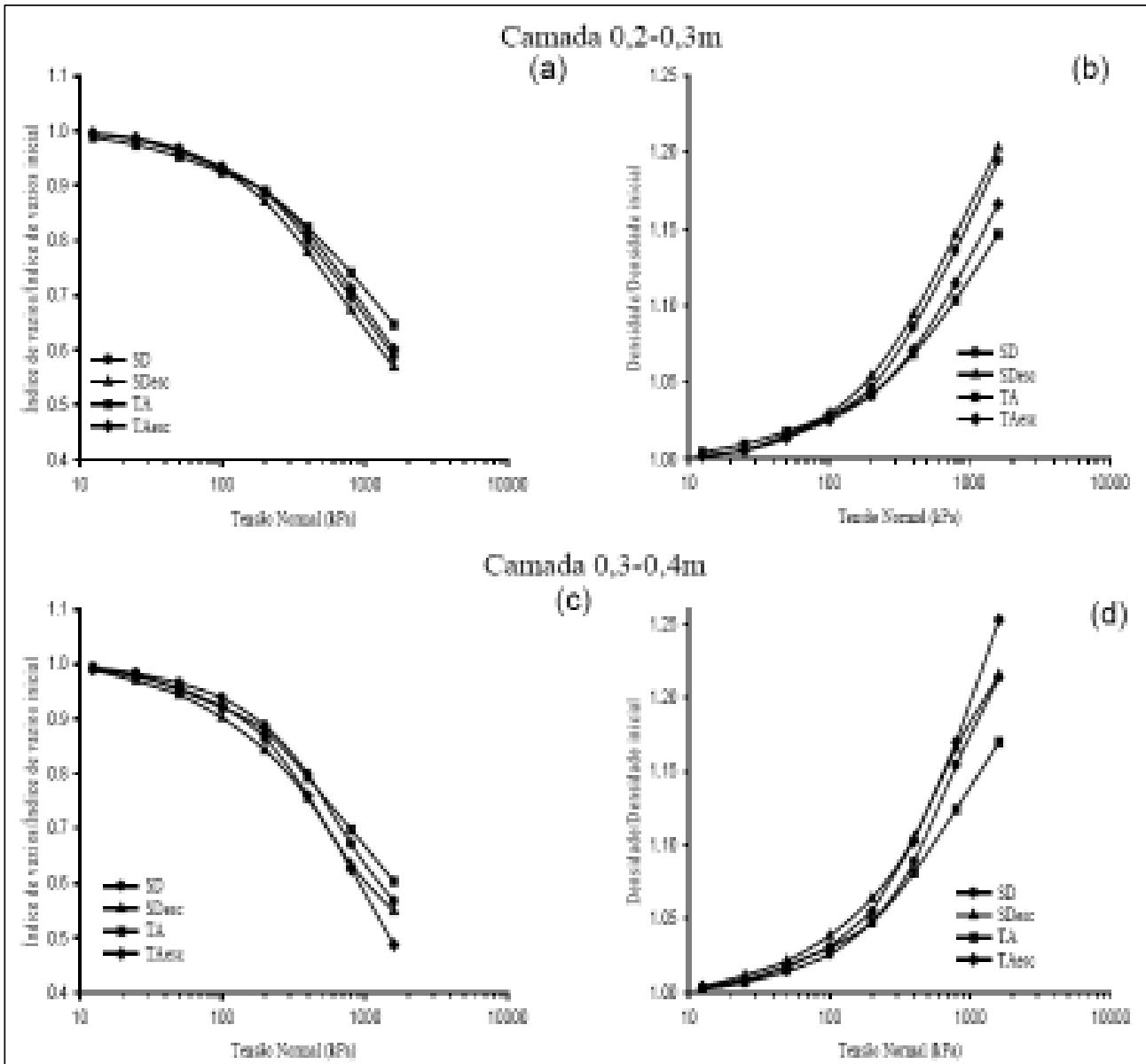

(c)

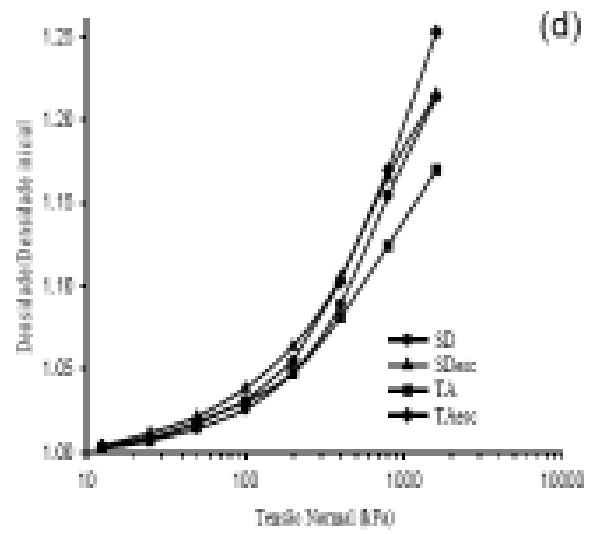

Figura 2 - Curva de compressão do solo normalizada nas camadas de 0,2-0,30m e 0,30-0,40m de acordo com a variação do índice de vazios $(\mathrm{a}, \mathrm{c})$ e com a densidade do solo $(\mathrm{b}, \mathrm{d})$. SD: semeadura direta, TA: tráfego adicional, SDesc: semeadura direta escarificado, TAesc: tráfego adicional escarificado.

200kPa aplicadas ao solo. Quanto maior o estado de compactação, menor será a deformação do solo após a aplicação de uma pressão, pois este pode estar próximo de sua densidade máxima e também menor será sua susceptibilidade à compactação (SUZUKI et al., 2008).

Diferenças significativas ocorreram para as variáveis densidade do solo e índice de vazios nas camadas abaixo da linha de atuação do escarificador (Tabela 1). A densidade aumentou e o índice de vazios reduziu nos tratamentos que foram trafegados (TA e TAesc) em relação aos tratamentos SD e SDesc na camada de 0,2-0,3m. Nessa mesma camada, quando analisado o efeito da ponteira do escarificador no solo, diferenças estatísticas para as variáveis índice de vazios e densidade não foram observadas. Na camada seguinte $(0,3-0,4 \mathrm{~m})$, os maiores valores de densidade do solo e os menores valores de índice de vazios ocorreram no tratamento TA, sendo que este não foi estatisticamente diferente ao TAesc. Os menores valores de densidade e índice de vazios ocorreram nos tratamentos SD e SDesc, sendo que o último não difere do tratamento TAesc. Ao comparar o efeito da haste do escarificador em subsuperfície, resultado semelhante à camada adjacente, foram observadas diferenças estatísticas significativas entre os tratamentos SD e SDesc que nos tratamentos TA e TAesc não ocorreram. Novamente, os valores de densidade do solo observados estão abaixo do considerado crítico ao desenvolvimento de plantas por REICHERT et al. (2009b) para solos com teor de argila de aproximadamente $200 \mathrm{~g} \mathrm{~kg}^{-1}$.

Não foram observadas diferenças significativas nos valores de pressão de preconsolidação encontrados abaixo da linha de atuação da haste escarificadora $(0,20-0,30 \mathrm{~m})$ (Tabela 1), ou seja, uma única passada da haste não transmitiu

Ciência Rural, v.42, n.2, fev, 2012. 
tensões ao solo que poderiam ter elevado seu estado de compactação, além do fato de o escarificador atuar sustentado por rodas niveladoras, impedindo que esse transmita maiores pressões ao solo. $\mathrm{O}$ menor e os maiores valores de coeficiente de compressão foram encontrados, respectivamente, nos tratamentos TA e $\mathrm{SD}$ e SDesc, enquanto que o tratamento TAesc apresentou valores intermediários. Por sua vez, na camada de $0,30-0,40 \mathrm{~m}$, a maior pressão de preconsolidação foi encontrada no tratamento $\mathrm{SD}$, que diferiu dos demais tratamentos. Quanto ao coeficiente de compressão, os maiores valores foram observados nos tratamentos SD e TAesc, sendo que este último não se distinguiu estatisticamente do tratamento SDesc e este, por sua vez, não foi diferente do tratamento TA.

Isso revela que as pressões aplicadas ao solo chegaram a mais de $0,20 \mathrm{~m}$ de profundidade, pois os menores valores de índice de compressão foram encontrados nos tratamentos que sofreram tráfego adicional. Esse fato pode ser explicado pelo aumento do número de contatos entre cada agregado em face ao aumento da pressão aplicada até o momento em que os agregados se rompam e o solo adquira uma estrutura maciça, com menor susceptibilidade à compactação (LARSON \& GUPTA 1980).

A escarificação aumentou a suscetibilidade à compactação nas parcelas com compactação adicional. Esse comportamento vai ao encontro do observado neste mesmo solo por MENTGES et al. (2010) ao avaliar a condutividade hidráulica do solo saturado, em que a escarificação elevou em 325\% os valores de condutividade, evidenciando os efeitos positivos da ação da haste escarificadora também abaixo da sua linha de atuação.

Na camada de 0,20-0,30m, o índice de vazios (Figura 2A) foi reduzido de forma semelhante para todos os tratamentos, sendo perceptíveis maiores diferenças a partir da aplicação de cargas de $400 \mathrm{kPa}$ às amostras. A partir desse momento, a redução no índice de vazios foi maior nos tratamentos SD e SDesc. Além disso, analisando o manejo do solo, observa-se que os tratamentos que sofreram escarificação (SDesc e TAesc) apresentaram maior redução no índice de vazios do que os tratamentos não mobilizados mecanicamente (SD e TA, respectivamente). Na camada de 0,30-0,40m (Figura 2C), um comportamento semelhante foi observado, porém com alterações no índice de vazios a partir de $200 \mathrm{kPa}$, concordando com os menores valores de pressão de preconsolidação observados nessa camada, sendo possível observar efeitos benéficos da escarificação em profundidades maiores do que a alcançada pela haste escarificadora.

\section{CONCLUSÃO}

A intensidade de tráfego de $24,67 \mathrm{Mg} \mathrm{km}$ ha $^{-1}$ reduziu a suscetibilidade do solo à compactação e elevou a capacidade de suporte de carga elevada até a profundidade de $0,20 \mathrm{~m}$.

Uma única escarificação não eleva o estado de compactação, mas aumenta a suscetibilidade à compactação do solo abaixo da linha de atuação da haste escarificadora em solo de textura franco arenosa sob semeadura direta.

\section{REFERÊNCIAS}

ABNT. NBR 12007: Ensaio de adensamento unidimensional. Rio de Janeiro, 1990. 13p.

ALAKUKU, L. et al. Prevention strategies for field trafficinduced subsoil compaction: a review. Part 1. Machine/soil interactions. Soil and Tillage Research, v.73, p.145-160, 2003. Disponível em: <http://www.sciencedirect.com/science/ article/pii/S0167198703001077>. Acesso em: 31 out. 2011. doi: $10.1016 / \mathrm{S} 0167-1987(03) 00107-7$.

BLAKE, G.R.; HARTGE, K.H. Bulk density. In: KLUTE, A. Methods of soil analysis: physical and mineralogical methods. 2.ed. Madison: American Society of Agronomy, 1986. p.363-375.

CAMARA, R.K.; KLEIN, V.A. Escarificação em plantio direto como técnica de conservação do solo e da água. Revista Brasileira de Ciência do Solo, v.29, p.789-796, 2005. Disponível em: <http://www.scielo.br/pdf/rbcs/v29n5/27890.pdf>. Acesso em: 31 out. 2011. doi: 10.1590/S010006832005000500014 .

COHRON, G.T. Force's causing soil compaction. In: BARNES, K.K. Compaction of agricultural soils. Michigan: ASAE, 1971. p.106-124.

DIAS JUNIOR, M.S.; PIERCE, F.J. O processo de compactação do solo e sua modelagem. Revista Brasileira de Ciência do Solo, v.20, p.175-182, 1996.

EMBRAPA. Centro Nacional de Pesquisa em solos. Sistema brasileiro de classificação de solos. Brasília, 2006. 412p.

GENRO JUNIOR, S.A. et al. Variabilidade temporal da resistência à penetração de um Latossolo argiloso sob semeadura direta com rotação de culturas. Revista Brasileira de Ciência do Solo, v.28, p.477-484, 2004. Disponível em: <http:// www.scielo.br/pdf/rbcs/v28n3/a09v28n3.pdf $>$. Acesso em: 31 out. 2011. doi: 10.1590/S0100-06832004000300009.

HÅKANSSON, I. Machinery-induced compaction of arable soils: incidence, consequences, counter-measures. Uppsala, Sweden: Dept. of Soil Sciences, Division of Soil Management, 2005. 153p.

HOLTZ, R.D.; KOVACS, W.D. An introduction to geotechnical engineering. New Jersey: Prentice-Hall, 1981. $733 \mathrm{p}$.

Ciência Rural, v.42, n.2, fev, 2012. 
HORN, R.; FLEIGE, H. A method for assessing the impact of load on mechanical stability and on physical properties of soils. Soil and Tillage Research, v.73, p.89-99, 2003. Disponível em: $\quad<$ http://www.sciencedirect.com/science/article/pii/ S0167198703001028>. Acesso em: 31 out. 2011. doi: 10.1016 S0167-1987(03)00102-8.

LARSON, W.E.; GUPTA, S.C. Estimating critical stress in unsaturated soils from changes in pore water pressure during confined compression. Soil Science Society of America Journal, v.44, p.1127-1132，1980.

LIMA C.L.R. et al. Compressibilidade de um solo sob sistemas de pastejo rotacionado intensivo irrigado e não irrigado. Revista Brasileira de Ciência do Solo, v.28, p.945-951, 2004. Disponível em: <http://www.scielo.br/pdf/rbcs/v28n6/ 22915.pdf>. Acesso em: 31 out. 2011. doi: 10.1590/S010006832004000600002

MENTGES, M.I. et al. Propriedades físico-hídricas do solo e demanda energética de hastes escarificadora em Argissolo compactado. Pesquisa Agropecuária Brasileira, v. 45 p.315-321, 2010. Disponível em: <http://www.scielo.br/pdf/ pab/v45n3/v45n3a12.pdf>. Acesso em: 31 out. 2011. doi: 10.1590/S0100-204X2010000300012.

NIMER, E. Climatologia do Brasil. 2.ed. Rio de Janeiro: IBGE, Departamento de Recursos Naturais e Estudos Ambientais, 1989. 442p.

REICHERT, J.M. et al. Compactação do solo em sistemas agropecuários e florestais: identificação, efeitos, limites críticos e mitigação. In: CERETTA, C.A. et al. Tópicos em ciência do solo. Viçosa: Sociedade Brasileira de Ciência do Solo, 2007. V.5, p.49-134.

REICHERT, J.M. et al. Variação temporal de propriedades físicas do solo e crescimento radicular de feijoeiro em quatro sistemas de manejo. Pesquisa Agropecuária Brasileira, v.44, p.310-319, 2009a. Disponível em: <http://www.scielo.br/ pdf/pab/v44n3/v44n3a13.pdf>. Acesso em: 31 out. 2011. doi: 10.1590/S0100-204X2009000300013.

REICHERT, J.M. et al. Reference bulk density and critical degreeof-compactness for no-till crop production in subtropical highly weathered soils. Soil and Tillage Research, v.102, p.242254, 2009b. Disponível em: <http://www.sciencedirect.com/ science/article/pii/S0167198708001025>. Acesso em: 31 out. 2011. doi: 10.1016/j.still.2008.07.002.

REINERT, D.J. COMPRESS - Software e proposta de modelo para descrever a compressibilidade dos solos e seus parâmetros. In: CONGRESSO BRASILEIRO DE CIÊNCIA DO SOLO, 29., 2003, Viçosa, MG. Anais... Viçosa, MG: Sociedade Brasileira de Ciência do Solo, 2003. 1 CD-ROM.

SILVA, A.J.N.; CABEDA, M.S.V. Compactação e compressibilidade do solo sob sistemas de manejo e níveis de umidade. Revista Brasileira de Ciência do Solo, v.30, p.921-930, 2006. Disponível em: Acesso em: <http:// www.scielo.br/pdf/rbcs/v30n6/a01v30n6.pdf>. 31 out. 2011. doi: 10.1590/S0100-06832006000600001.

SILVA, V.R. et al. Susceptibilidade à compactação de um Latossolo Vermelho-Escuro e de um Podzólico VermelhoAmarelo. Revista Brasileira de Ciência do Solo, v.24, p.239-249, 2000.

STONE, L.F.; SILVEIRA, P.M. Efeitos do sistema de preparo na compactação do solo. Pesquisa Agropecuária Brasileira, v.34, p.83-91, 1999.

SUZUKI, L.E.A.S. et al. Estimativa da susceptibilidade à compactação e do suporte de carga do solo com base em propriedades físicas de solos do Rio Grande do Sul. Revista Brasileira de Ciência do Solo, v.32, p.963-973, 2008. Disponível em: <http:/ /www.scielo.br/pdf/rbcs/v32n3/a06v32n3.pdf>. Acesso em: 31 out. 2011. doi: 10.1590/S0100-06832008000300006. 